\title{
Relevância dos periódicos de saúde coletiva em informar a pesquisa, a educação, os serviços de saúde e a cidadania
}

\author{
The relevance of Public Health Journals in informing research, \\ education, health services, and citizenship
}

Moisés Goldbaum (https://orcid.org/0000-0002-8049-7824) ${ }^{1}$

José Leopoldo Ferreira Antunes (https://orcid.org/0000-0003-3972-9723) ${ }^{2}$

Kenneth Rochel Camargo Júnior (https://orcid.org/0000-0003-3606-5853) ${ }^{3}$

\footnotetext{
${ }^{1}$ Faculdade de Medicina, Universidade de São Paulo (USP). Av. Dr. Arnaldo 455, Cerqueira César. 01246903 São Paulo SP Brasil. mgoldbau@usp.br

${ }^{2}$ Faculdade de Saúde Pública, USP. São Paulo SP Brasil.

${ }^{3}$ Instituto de Medicina Social, Universidade do Estado do Rio de Janeiro. Rio de Janeiro RJ Brasil.
}

\begin{abstract}
This text presents in a synthetic manner the discussions of the working group of the same name, held during the international conference commemorating the twenty years of the SciELO Program. The objective is to inform the Public Health professional field about chronic problems affecting scientific periodicals in Brazil - financing, classification of journals, the impact of published works, among others.
\end{abstract}

Key words Journal, Public health
Resumo Esse texto apresenta de modo sintético, as discussões do grupo de trabalho de mesmo nome, realizadas durante a conferência internacional comemorativa dos vinte anos do Programa SciELO. O objetivo é informar o meio profissional da saúde coletiva sobre problemas crônicos das publicações científicas no Brasil - financiamento, classificação das revistas, impacto dos trabalhos publicados, entre outros.

Palavras-chave Publicação periódica, Saúde coletiva 
Em 2018, o Programa SciELO celebrou vinte anos de funcionamento contínuo e serviços prestados à publicação científica. $\mathrm{O}$ evento comemorativo, na última semana de setembro, contou com a participação de pesquisadores atuando no país e no exterior, editores de revistas científicas de todas as áreas de conhecimento e profissionais dos sistemas de indexação. Integrado à conferência internacional, houve oficinas de trabalho no dia 25 de setembro, reunindo editores de todos os países participantes da Rede SciELO: África do Sul, Argentina, Bolívia, Brasil, Chile, Colômbia, Costa Rica, Cuba, Equador, Espanha, México, Paraguai, Peru, Portugal, Uruguai e Venezuela.

O grupo de trabalho denominado "Relevância dos periódicos de saúde coletiva em informar a pesquisa, a educação, os serviços de saúde e a cidadania" contou com a participação de expressivo número de editores dos periódicos da área que são publicados no Brasil, incluindo não apenas revistas indexadas na Coleção SciELO, mas também representantes de revistas ainda não indexadas.

Esse texto visa apresentar os documentos técnicos elaborados previamente para compor a pauta temática da reunião e sintetizar a discussão ocorrida no evento. Esses documentos técnicos foram elaborados com o intuito de documentar a atual conjuntura vivenciada pelo meio editorial e contribuir para o desenvolvimento da área, preparando editores e pesquisadores com interesse em publicação científica para os principais desafios a serem enfrentados.

\section{Pauta temática}

O primeiro documento técnico ${ }^{1}$ traça um diagnóstico das dificuldades de financiamento que os periódicos de saúde coletiva enfrentam para se manter. $\mathrm{O}$ segundo $^{2}$ focaliza as desigualdades de gênero na pesquisa e na produção científica no cenário internacional e nacional, propugnando iniciativas para o monitoramento e superação dessas desigualdades. $\mathrm{O}$ terceiro $^{3}$ apresenta a proposta recentemente discutida pela CAPES para reformular a classificação Qualis das revistas de saúde coletiva. $\mathrm{O}$ quarto texto ${ }^{4}$ analisa características formais e de conteúdo dos artigos de maior impacto na área, em relação àqueles que não recebem citações.

O compartilhamento em acesso aberto das bases de dados utilizadas nos artigos publicados nas revistas de saúde coletiva tem sido cada vez mais solicitado aos autores. Esse é o tema do quinto documento ${ }^{5}$ dessa série, o qual discute as condições necessárias para viabilizar essa demanda.

A internacionalização dos periódicos de saúde coletiva é o sexto tópico ${ }^{6}$; discute-se como dinamizar a comunicação científica, incrementando a visibilidade internacional dos artigos publicados no Brasil. O sétimo documento ${ }^{7}$ aborda a contribuição dos periódicos de saúde coletiva para o planejamento e gestão dos serviços de saúde.

O debate travado após as apresentações acentuou e aprofundou os temas em pauta.

\section{Posicionamentos em debate}

No tocante ao financiamento dos periódicos da saúde coletiva, apontou-se que as dificuldades enfrentadas não são exclusivas e estendemse aos demais campos disciplinares. Registrou-se o escasso volume de recursos financeiros aportados pelas agências de fomento; os montantes disponibilizados anualmente não são sequer suficientes para viabilizar a edição de um único fascículo das revistas. Em 2015, o CNPq destinou para apoio editorial apenas $0,06 \%$ de seu orçamento aplicado em fomento à pesquisa. Quanto às agências estaduais, registrou-se que a FAPESP concede apoio para custear publicações científicas das pesquisas que financia, quando a revista cobra para a edição, o que representa um apoio indireto aos periódicos. A plenária entendeu que não há políticas públicas de amplitude nacional para a sustentação dos programas editoriais. Assim, o grupo concluiu ser necessário propugnar diretrizes governamentais para prover o país de políticas públicas consistentes e duradouras na área de ciência, tecnologia e inovação, especificamente contemplando a divulgação do conhecimento produzido no país.

Assinalou-se, com ênfase, que a Coleção SciELO é uma instância central na sustentabilidade e visibilidade dos periódicos editados no país. A atuação do SciELO na edição, divulgação e indexação da produção científica nacional tem sido preponderante. Sublinhou-se a necessidade de garantir recursos para sua sustentação, evitando ou minimizando o elevado custo cobrado por Publishers do exterior. Lamentou-se a quase extinção do protagonismo da BIREME/OPAS nessa área, considerando que essa organização detém suficientes mecanismos e capacidade técnica para orientar e apoiar as veredas do desenvolvimento científico e tecnológico em saúde. Concluiu-se ser indispensável estimular o aumento criterioso da indexação dos periódicos, bem como manter e aprimorar continuamente essa base. Apontou- 
se, também, que novas propostas para o aprimoramento dos programas editoriais não devem contemplar aumento de custos, especialmente na atual conjuntura.

Quanto à análise dos critérios SciELO de indexação, assinalou-se que os periódicos de saúde coletiva, dentro de suas possibilidades e com ressalvas, vêm conseguindo atendê-los. Parte dos periódicos já aderiu ao fluxo contínuo de indexação, suprimindo a divisão em fascículos dos volumes anuais, medida que tem se mostrado proveitosa para os que já a adotaram. Praticamente todos editam seus artigos de modo bilíngue, em português e inglês, mas são obrigadas a processos contratuais que dependem de licitação, tornando-as vulneráveis a traduções de má qualidade. A exigência de constituir corpo editorial com pesquisadores atuando no exterior tem sido contemplada, apesar das dificuldades inerentes a esta ação. Apesar do sistema de submissão utilizar o idioma inglês, a busca de revisores sediados no exterior para a emissão de pareceres ad hoc também esbarra na dificuldade do idioma, pois a maioria dos originais é submetida em português e apenas os artigos aprovados são vertidos para o inglês. No tocante à publicação de artigos provenientes do exterior, depara-se com uma situação peculiar; pois muitos desses artigos são de má qualidade, e acabam sendo rejeitados em rito sumário pelos editores científicos. Nesse sentido, a plenária sugeriu suprimir esse item (publicação de artigos provenientes do exterior) como critério de avaliação dos periódicos.

A plenária deteve-se na discussão de dificuldades do processo editorial. A edição científica não dispõe de um sistema profissional. O trabalho é feito de modo voluntário por membros da comunidade científica que atuam, ora como autores, ora como revisores, ora como editores. Ainda que tenhamos conseguido, com muito empenho, corresponder ao trabalho exigido, essa condição não garante uma administração racional do processo editorial em longo prazo. Destacou-se a grande dificuldade de todos os periódicos em buscar revisores para todos os artigos submetidos. Para não poucos artigos submetidos, tem sido necessário indicar até mais de dez revisores até obter o suficiente para a tomada de decisão editorial. Em parte, isso é devido à sobrecarga vivenciada pelos pesquisadores, mas tem gerado transtornos importantes e atraso significativo na condução do processo editorial. A plenária manifestou ser compreensível, porém não justificável, que os mesmos profissionais que recusam repetidamente avaliar os manuscritos acabem aceitando fazê-lo para periódicos estrangeiros, especialmente aqueles de ponta. Para minimizar esta dificuldade, sugeriu-se procurar estratégias de valorização do trabalho efetuado pelos revisores, por exemplo, incluindo o registro dessa atividade na avaliação dos programas de pós-graduação efetuada pela CAPES. Lembrase, ainda, que a avaliação dos periódicos depende fortemente do financiamento, o qual, como apontado, tem sido cronicamente insuficiente.

A proposição de diretrizes editoriais da ciência aberta, em especial a proposição de submeter os artigos via repositórios de "preprint", foi considerada ponto importante, que merece ampla difusão, debate e cuidados na aplicação. Entendeuse que a submissão via repositórios de preprint, ainda que imprima maior agilidade ao processo editorial, não pode ser a única porta de entrada das revistas, para não inviabilizar as formas tradicionais de submissão. Conquanto possam ficar permanentemente disponíveis nos repositórios de preprint, essa medida pode atenuar o procedimento editorial de rejeição em rito sumário empregado pelas revistas. A identificação nominal dos revisores e a abertura dos pareceres elaborados devem ser facultativas, dependendo da autorização de todos os envolvidos, tanto dos autores, como dos revisores. Discutiu-se a possibilidade de os artigos disponíveis nos repositórios de preprint serem citados antes mesmo de publicados, o que poderia repercutir nos índices tradicionais de impacto das publicações. Foram propostos experimentos editoriais inovadores, como o estabelecimento de linhas temáticas de submissão envolvendo um conjunto de revistas, para incentivar a comunidade científica a submeter trabalhos nessa modalidade.

Ainda com relação à pauta de tópicos sobre ciência aberta, várias questões não foram resolvidas e não há consenso quanto a sua adoção. Destacou-se que a submissão em acesso aberto das bases de dados utilizadas na elaboração dos artigos publicados deve ser acompanhada pela apresentação das rotinas estatísticas a serem empregadas na análise, o dicionário das variáveis utilizadas, o protocolo de pesquisa e, em caso de inquéritos, o questionário aplicado. Em relação às pesquisas utilizando dados qualitativos, sublinhou-se a complexidade da coleta de dados, a qual não necessariamente corresponde aos padrões utilizados nas pesquisas, por exemplo, de natureza epidemiológica. Sugeriu-se a disponibilização de dados minimamente necessários para conferir a análise efetuada. Restou inconclusa a questão de como a publicação da base de dados 
poderá ser referenciada bibliograficamente. Da perspectiva da ética de pesquisa em seres humanos, recomendou-se consultar a Comissão Nacional de Ética em Pesquisa (CONEP) quanto à necessidade de incluir no Termo de Consentimento Livre e Esclarecido (TCLE) a informação de que os dados levantados poderão ser utilizados para outras finalidades por parte de outros pesquisadores. Chamou-se a atenção de que a exposição de dados não pode provocar danos, especialmente, de ordem social, para os participantes da pesquisa. Dentre as indagações, restaram sem resposta quais repositórios deverão ser utilizados e que instituições deverão mantê-los. Também ficou irresoluta a garantia do uso adequado dos dados, haja vista a possibilidade de instituições mais bem estruturadas tornarem viável a reunião de dados de diferentes origens, por meio de técnicas de big data e machine learning.

Por fim, mas não menos importante, a reunião plenária discutiu a proposição de mudanças no critério de classificação dos periódicos, conforme consignado do documento técnico que registrou a proposta discutida no início de 2018 pelo Conselho Técnico-Científico da Educação Superior (CTC-ES) da CAPES. Foi consensual o estranhamento da proposição de retirar ou diminuir o protagonismo do SciELO como base de indexação para classificação dos periódicos na composição do Webqualis. O grupo considerou que o significado maior desta proposta é desvalorizar e desqualificar a Coleção SciELO e todos seus periódicos. Criada para dar maior visibilidade à produção científica regional, a Coleção SciELO vem atendendo às especificidades de nossa realidade latino-americana, deslocando o foco comercial das bases internacionais para o interesse acadêmico das revistas científicas editadas no país. É ineludível que o SciELO tem favorecido a internacionalização da produção científica do Brasil, perspectiva tão perseguida e desejada pela comunidade científica. Considerou-se que essa iniciativa, na prática, esmaece a perspectiva de internacionalizar a produção científica do país. A reunião plenária reconheceu a importância da avaliação CAPES e seu enorme impacto na indução do desenvolvimento do ensino e da pesquisa no Brasil; mas reiterou a necessidade de que a avaliação não induza a desvalorização dos programas editoriais no país. Houve consenso de que a proposta discutida no CTC-ES da CAPES terá ampla repercussão negativa para as revistas científicas editadas no Brasil. Com base nos dados apresentados no documento técnico que consta desse dossiê, verifica-se que ampla maioria (77\%) dos artigos científicos informados pelos Programas de Pós-Graduação em saúde coletiva no último quadriênio de avaliação da CAPES foi publicada em revistas no Brasil. Acredita-se que a desqualificação das revistas como veículo de divulgação científica seja igualmente prejudicial para os Programas de Pós-Graduação. Considerando estes argumentos, o grupo decidiu expressar rejeição à proposta apresentada. 


\section{Colaboradores}

M Goldbaum, JLF Antunes e KR Camargo Júnior participaram igualmente em todas as etapas de elaboração do artigo.

\section{Referências}

1. Almeida MF, Goldbaum M. Sustentabilidade e financiamento dos periódicos de saúde coletiva. SciELO 20 Years Repository 2018; 101:69. Disponível em: http://repository.scielo20.org/documents/article/ view/101/69

2. Garcia LP. A participação feminina no meio editorial da saúde coletiva. SciELO 20 Years Repository 2018; 109:75. Disponível em: http://repository.scielo20.org/ documents/article/view/109/75

3. Barata RB. Os periódicos de Saúde Coletiva e o Webqualis: situação atual e a nova avaliação. SciELO 20 Years Repository 2018; 91:61. Disponível em: http:// repository.scielo20.org/documents/article/view/91/61

4. Cuenca AMB, Barbosa MMAL, França-Jr I. Artigos mais citados e os não citados das revistas em saúde pública: o que os editores têm a ver com isso? SciELO 20 Years Repository 2018; 99:71. Disponível em: http:// repository.scielo20.org/documents/article/view/99/71

5. Barros AJD, Horta BL. Compartilhamento de dados de pesquisa: para ser ético, equitativo e responsável há um grande investimento a fazer. SciELO 20 Years Repository 2018; 95:65. Disponível em: http://repository. scielo20.org/documents/article/view/95/65

6. Antunes JLF, Barros AJD, Minayo MCS. Caminhos da internacionalização dos periódicos de saúde coletiva. SciELO 20 Years Repository 2018; 97:67. Disponível em: http://repository.scielo20.org/documents/article/ view/97/67

7. Souza LEPF. Contribuição dos periódicos de saúde coletiva para o planejamento e a gestão dos serviços de saúde. SciELO 20 Years Repository 2018; 121:87. Disponível em: http://repository.scielo20.org/documents/article/view/121/87

Artigo apresentado em 05/12/2018

Aprovado em 14/07/2019

Versão final apresentada em 16/07/2019

Editores-chefes: Romeu Gomes, Antônio Augusto Moura da Silva 
